\title{
El habitar en altura en la Córdoba moderna del siglo $X X^{1}$.
}

\author{
Tall dwelling in twentieth century modern Córdoba.
}

Cómo citar:

Carmignani, M (2018). El habitar en altura en la Córdoba moderna del siglo XX. Designia 6 (1), 99-115.

\author{
${ }^{1}$ Este artículo de reflexión parte de múltiples investi- \\ gaciones realizadas por la Cátedra de Historia de \\ la Arquitectura Latinoamericana de la Facultad de \\ Arquitectura, Urbanismo y Diseño de la Universidad \\ Nacional de Córdoba (UNC), Argentina. \\ *Arquitecta FAUDI, UNC, 2007. Córdoba, Argentina. \\ Magister "Conservación y Rehabilitación del \\ Patrimonio Arquitectónico”, FAUDI, UNC 2016. \\ Docente Investigador Categoría 5, FAUDI y Profesor \\ asistente Cátedra de "Historia de la Arquitectura y \\ el Urbanismo Latinoamericanos III A, UNC. Prof. \\ Asistente, Cátedras de "Historia del Arte B" y "Arquitec- \\ tura y Urbanismo”, Facultad de Derecho. UNLZ. \\ maritacarmignani@gmail.com \\ ORCID: 0000-0002-9658-9926
}

Palabras clave:

Modernidad, vivienda colectiva, identidad, transculturación, Latinoamérica.

\section{Key words:}

Modernity, collective housing, identity, transculturation, Latin America.

\section{Recibido: $21 / 10 / 2017$}

Aceptado: 08/08/2018

\section{Resumen:}

El presente artículo expone reflexiones acerca de las tipologías residenciales colectivas que durante las primeras décadas del siglo XX se crearon en Argentina, particularmente en la ciudad de Córdoba, a partir de procesos de transculturación de modelos del Movimiento Moderno procedentes de realidades europeas. La temática se aborda desde el significado ontológico del habitar, para ordenar luego la vivienda en altura en clasificaciones de tiempo y espacio en que el interés particular se acentúa en el componente antropológico y geográfico latinoamericano. Las propuestas logradas reflejan cómo las búsquedas se adaptan a los modelos universales o generan reelaboraciones propias para conferirles un carácter singular y regional, en medio de un fenómeno de modernización definido por nuevos modos de vida, nueva cultura urbana y nuevas condicionantes del habitar. 
This paper reflects on collective residential typologies created during the first decades of the 20th century in Argentina, particularly in Córdoba city, on the basis of transculturation processes of the Modern Movement' European models. After approaching the ontological meaning of inhabiting, the tall dwelling is sorted into time and space classifications where the Latin American anthropological and geographic component is accentuated as a particular interest. The built proposals reflect how the searches either adapt themselves to universal models or generate own works which are given a singular and regional character amidst a modernization phenomenon defined by new lifestyles, urban culture and conditions to inhabit.

Desde la cátedra "Historia de la Arquitectura y el Urbanismo Latinoamericano" de la Facultad de Arquitectura de la UNC, se reconoce la necesidad de profundizar al momento de analizar, pensar y diseñar un tipo esencial y referente por excelencia de identidad, como es la vivienda latinoamericana. Con esta orientación, al entender en la historia la base de nuestro presente y de nuestro futuro, cabe preguntar: ¿cómo saber qué arquitectura y qué vivienda tenemos y queremos hoy, si no sabemos cómo se conforma el tejido que mayoritariamente cubre una ciudad?

La Historia de la Arquitectura permite, sobre todo, reflexionar acerca de tipos, modificaciones y transformaciones de la vivienda a través del tiempo. Recuperamos aquí a Romero (1997), para quien el conocimiento de tales cambios y de las expresiones territoriales observables en las formas de habitar puede aportar claves para ulteriores análisis en las dimensiones cultural y social, pues el espacio doméstico constituye un registro privilegiado de huellas, comportamientos y acciones de los individuos. En relación con este particular, este trabajo adoptó una metodología de análisis de tipo cualitativo exploratorio con el fin de identificar las características representativas del habitar en la vivienda argentina moderna de las grandes urbes. Respecto al enfoque fenomenológico prevaleciente en la investigación, se entiende que este no parte del diseño de una teoría sino de la percepción del mundo conocido, a partir de la cual es posible interpretar y vincular distintos componentes de la realidad desde una visión compleja.

Se ha observado y analizado el uso de los espacios habitacionales y la relación del binomio tipología - ciudad a lo largo del periodo de estudio con el fin de identificar el rol protagónico de la vivienda moderna colectiva en la densificación de la trama y el tejido urbano. A su vez, se llevó a cabo el estudio de casos, es decir, el mapeo general, documental y gráfico de ejemplos puntuales -siempre vinculados a los entornos 
donde se originan- pero solo para fines de extraer conclusiones y modos comunes de hacer y pensar, sin abarcar el análisis convencional y pormenorizado de tipologías arquitectónicas. Se propone así indagar sobre el tipo residencial colectivo en la ciudad de Córdoba durante las primeras décadas del siglo XX con base en casos de estudio específicos, para lo cual se tiene en cuenta el habitar del hombre latinoamericano y la transculturación de modelos del Movimiento Moderno.

\section{EL HABITAR Y LA VIVIENDA}

Para comprender la tipología colectiva resulta esencial reflexionar antes acerca de la idea del habitar humano. Este no se reduce a estar en un espacio o lugar, sino que es una práctica fundamental. Además, ubica e instala al hombre en un tiempo y un contexto determinado para producir una serie de articulaciones entre las diversas maneras de vivir y de esperar vivir en los planos individual, familiar y colectivo. En la teoría del habitar formulada por Doberti (2008) se afirma:

\section{Lo propio y lo definitorio de la arquitectura es ser habitada, y lo propio y lo específico del habitar humano es su carácter histórico, mutable y múl- tiple. En los modos de ocupar el espacio para habitarlo se ponen en juego cuestiones políticas y sociales, biológicas y simbólicas, organizativas y ritua- les. En este sentido podemos decir que los modos de habitar, propuestos y dispuestos por las conformaciones que nos circundan, se definen como rasgos esenciales de nuestra identidad personal, grupal y cultural (p. 182).}

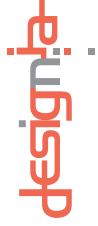

Respecto al habitar doméstico, este ha asumido desde sus orígenes un rol esencial en la cultura occidental. Para Taberna (2008), la vivienda no solo es el escenario donde ocurren acontecimientos trascendentes de la vida, sino que también en torno al hogar el grupo doméstico da forma al proyecto de su existencia. Más allá de ser un cobijo para sobrevivir a las inclemencias del medio ambiente, es un espacio posibilitador para cada persona del desarrollo de un sentido de su propio yo. Los muros delimitadores del entorno íntimo se convierten en expresión de su voluntad de permanecer y huella de su vida. En este contexto, el hombre puede ser definido como "el que habita" y la casa como el ámbito necesario y exclusivo para la integración de los pensamientos, los recuerdos y los sueños de quien vive en él. 
Por otra parte, desde una dimensión simbólica, la vivienda según Yujnovsky (1984) representa una conjunción de servicios que responde a necesidades humanas primordiales, entre ellas albergue, refugio y protección, como parte de un grupo social, un ambiente y un espacio. Alcalá (1995) sostiene además que a partir del hecho antropológico, dinámico e histórico, la vivienda reúne lo espacial, económico, social, político, institucional y cultural. A su vez, según afirma Iglesia (2006), es el sitio donde la persona experimenta un adentro y un afuera, una conciencia del interior y el exterior, completada con la presencia grupal familiar y la cotidianidad.

\section{LA IDENTIDAD CULTURAL EN LATINOAMÉRICA Y SU RELACIÓN CON LA TIPOLOGÍA RESIDENCIAL}

Es posible definir la identidad como la resultante de un particular modo de pensamiento y acción que diferencia a los hombres entre sí y se construye a través de su historia. Puede considerarse un valor emergente, con entidad propia en un universo limitado, en el cual determinadas variables se amalgaman armónicamente para producir una síntesis entre teoría y praxis. Dicho concepto está enmarcado en un tiempo y un espacio que configuran un particular ambiente humano en función de un sistema de valores y según su horizonte cultural.

La identidad cultural latinoamericana es dinámica y cambiante, permeable a circunstancias propias y exógenas en un proceso construido día a día, multifacético y continuo. Para Rojas Mix (2004) es un proyecto a futuro. Al respecto, cabe señalar que la vivienda en nuestra región a inicios del siglo XX evidencia claramente esas características al adherir a la vanguardia propuesta por el Movimiento Moderno (MoMo) europeo y, a la vez, incorporar la impronta de culturas particulares en ejemplos paradigmáticos de reelaboración y apropiación. Según Montaner (2011), la casa en Latinoamérica es recinto y paisaje, un universo creado por el hombre, quien acumula cosas, habita y desprende allí sus experiencias y búsquedas.

\section{LA MODERNIDAD Y EL PROCESO DE TRANSCULTURACIÓN EN ARGENTINA}

Para situarnos en el problema, recuperamos la teoría del MoMo europeo, en la cual -en consonancia con la idea de Le Corbusier-la vivienda puede ser sintetizada como "una máquina para ser habitada", una forma que responde a la función y a los cincos puntos de la Arquitectura formulados por el maestro en su búsqueda por asegurar la fluidez del espacio. No solo en Europa sino también en América, la Arquitectura moderna se expresa en múltiples declaraciones o manifiestos. 
En Argentina, sostienen Casal y Worden (2004), el ingreso de las teorías modernas se da mediante publicaciones europeas, el interés de los arquitectos del país por producir trabajos de calidad enmarcados en el movimiento y la promoción de obras y artículos en revistas nacionales. Algunas de estas adherían a los principios modernos mientras que otras manifestaban la inquietud por encontrar un equilibrio entre las tendencias internacionales y una producción propia argentina.

Con causas y consecuencias diversas, con fuerzas socioculturales actuantes capaces de transformar la hegemonía metropolitana, con resistencia por parte de algunos sectores, el MoMo se da con idéntica intensidad en el centro receptor-emisor, Buenos Aires, como en la periferia emergente, la ciudad de Córdoba.

Para Martínez Nespral (2012), la irrupción de la modernidad en el país se plasma en numerosos proyectos que privilegian la búsqueda de condiciones óptimas de habitación (iluminación, asoleamiento, interacción con espacios verdes), y el diseño con base en los principios corbusieranos, tales como las plantas libres y las terrazas jardín. Estos, sumados a la presencia de aventanamientos más amplios y de ambientes funcionales, manifiestan la transculturación del modelo. De acuerdo con Scarone (2008), si bien esta arquitectura generó presencias insoslayables en las ciudades, para el común de los habitantes representaba la intención y la voluntad de hacer de una elite pensante, perteneciente, a su vez, a una elite económica.

\section{EL HABITAR MODERNO EN CÓRDOBA: TIPOLOGÍA DE VIVIENDA DE DEPARTAMENTOS}

Entre finales del siglo XIX y comienzos del XX, el primer crecimiento de Córdoba a partir del núcleo histórico colonial lleva a superar el río y dominar las barrancas con la construcción de nuevos barrios, lo cual repercute sobre la red vial, la trama y el tejido. Colautti (2002) describe aquella ciudad de las primeras décadas del siglo XX como un modelo centrípeto donde la red del ferrocarril envolvía el trazado radial desde el centro hacia las barrancas. Se trataba de un centro geográfico en su propia provincia pero también para el país, dado su rol comercial con el resto del territorio.

Allí, las gestiones progresistas del gobernador Ramón J. Cárcano, particularmente durante su segunda gestión (1925-1928), y del intendente Emilio F. Olmos entre 1925 y 1929, proponen cambiar la fisonomía de la ciudad en aras de mejorar la calidad de vida y lograr una modernización. Uno de los proyectos contemplados es el ensanche de un tramo de la avenida Colón Olmos, donde además se levantan nuevas fachadas sobre la vereda norte (Díaz Terreno, s.f.). Estos fenómenos definen modos de vida, 
condiciones de habitar y espacios de uso, como también una naciente cultura urbana que otorga protagonismo al automóvil y adopta otros imaginarios. Estos van desde la confianza retórica en el futuro hasta la fantasía espiritual, pasan por resultados pragmáticos y se verifican en la transformación de renovados artefactos urbanos y redes de producción, circulación y consumo.

En las décadas de los treinta y los cuarenta, edificaciones en altura y equipamientos de cierta envergadura se suman a las construcciones de los años veinte. Los edificios de renta como el de la compañía de seguros La Sudamérica, el Mota Reyna y el de la compañía de seguros La Continental, localizados sobre la nueva avenida Colón Olmos, o el Minetti, primero en ser erigido sobre la diagonal Hipólito Irigoyen, inauguran la tipología de vivienda racionalista en altura.

Es pertinente considerar que antes de la Ley 13512 de 1948 o de Propiedad Horizontal, los inmuebles solo podían pertenecer a un propietario (persona física o jurídica) y los departamentos quedaban destinados al alquiler. Esto originó el edificio de renta, tipo surgido como expresión constructiva de una interpretación de la modernidad en cuanto a lo funcional, lo tecnológico y lo edificatorio, el cual busca satisfacer requerimientos del incipiente desarrollo de sectores medios que paulatinamente modifican sus modos de habitar. La modernización del hogar simplificó la disposición y el equipamiento y junto a la incorporación de avances tecnológicos, hicieron eficiente y confortable la vivienda moderna.

A continuación se presentan los casos de estudio que se han considerado como más representativos para el análisis de esta tipología. Una vez revisados, se reflexiona acerca de distintos aspectos arquitectónicos a los cuales remiten.

\section{Edificio de la compañía de Seguros La Sudamérica (1936)}

Avenida Colón 74. Arquitectos: Antonio Vilar y Jaime Roca. Destinado al uso residencial, cuenta con ocho niveles, locales comerciales en la planta baja y dos unidades habitacionales por piso. Su fachada presenta organización simétrica y racional a partir de un plano vertical en voladizo que enlaza los balcones y contrarresta las formas horizontales. 

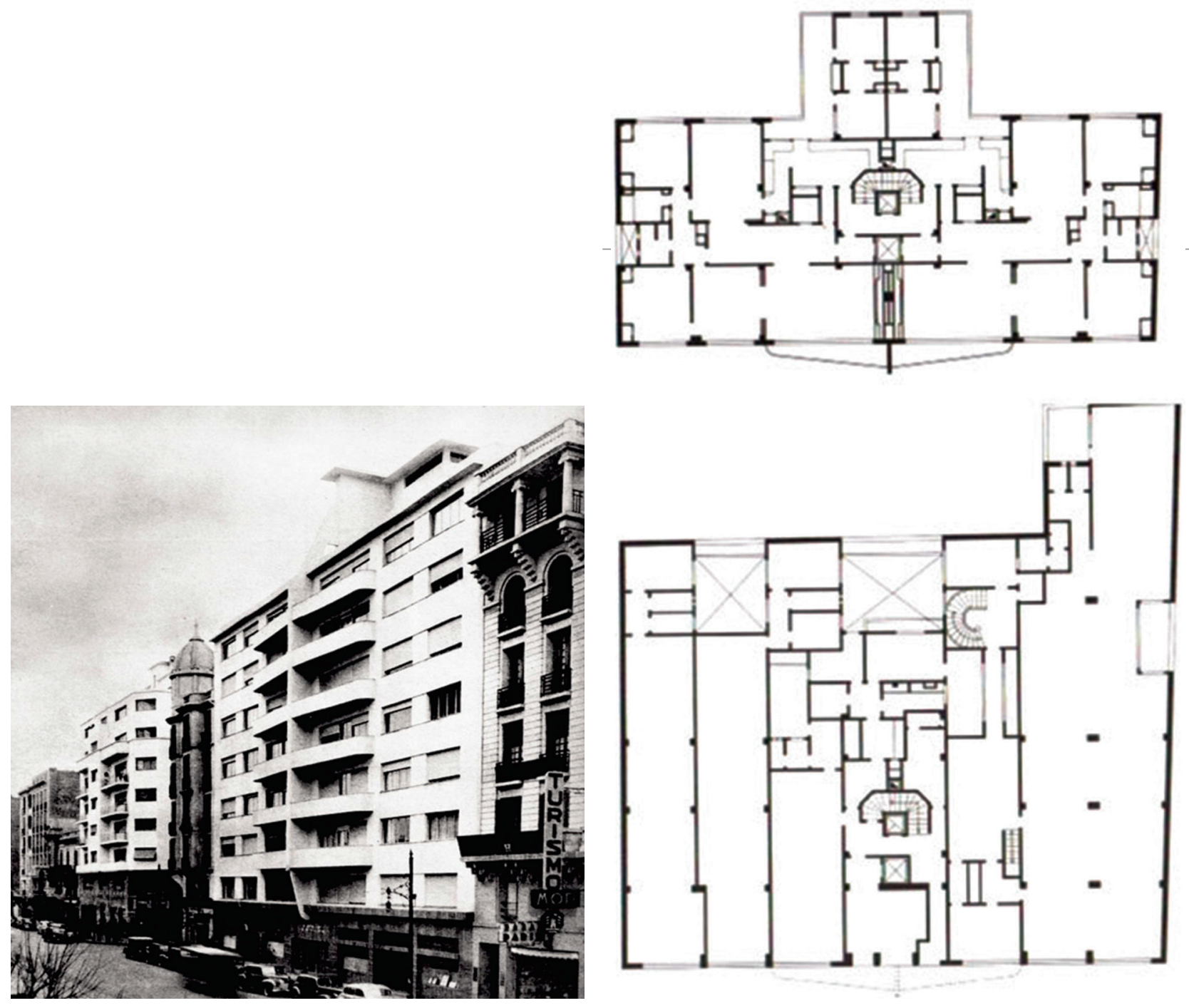

Figura 1. Fachada del edificio de la compañía de seguros La Sudamérica.

Figura 2. Plantas del edificio de la compañía de seguros La Sudamérica. 


\section{Edificio Mota Reyna (1938)}

Esquina en la Avenida Olmos y Alvear. Arquitecto: Jaime Roca. De uso residencial, posee locales comerciales en la planta baja y siete niveles con varias unidades habitacionales en cada uno. Su lenguaje remite al expresionismo alemán, especialmente a la obra de Mendelsohn: austeridad, simplicidad, planos curvos y apilamiento de planos llenos sobre vacíos son sus rasgos característicos.

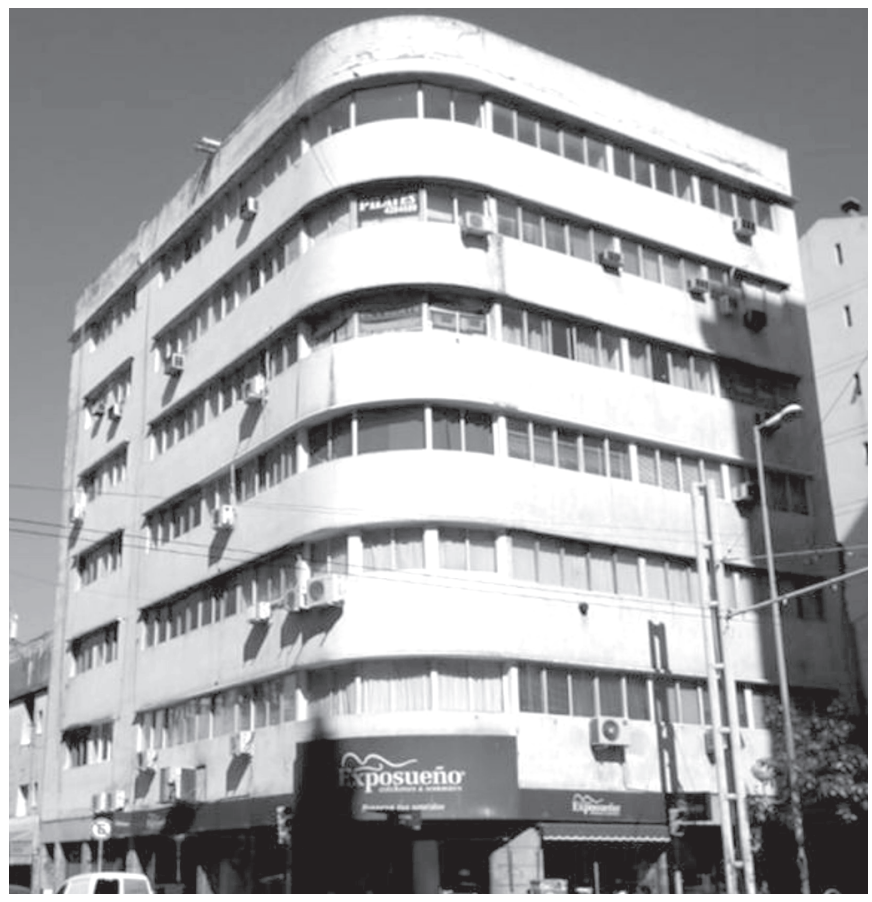

Figura 3. Edificio Mota Reyna. Fuente: autores. 
Edificio de la compañía de seguros La Continental (1938).

Esquina en la Avenida Colón y Rivera Indarte. Arquitecto: Jaime Roca. Tiene locales comerciales en la planta baja y siete niveles con dos unidades habitacionales por piso. Su lenguaje es austero y de planos limpios, con balcones curvos que remiten a la arquitectura racional y fachada sin organización simétrica.
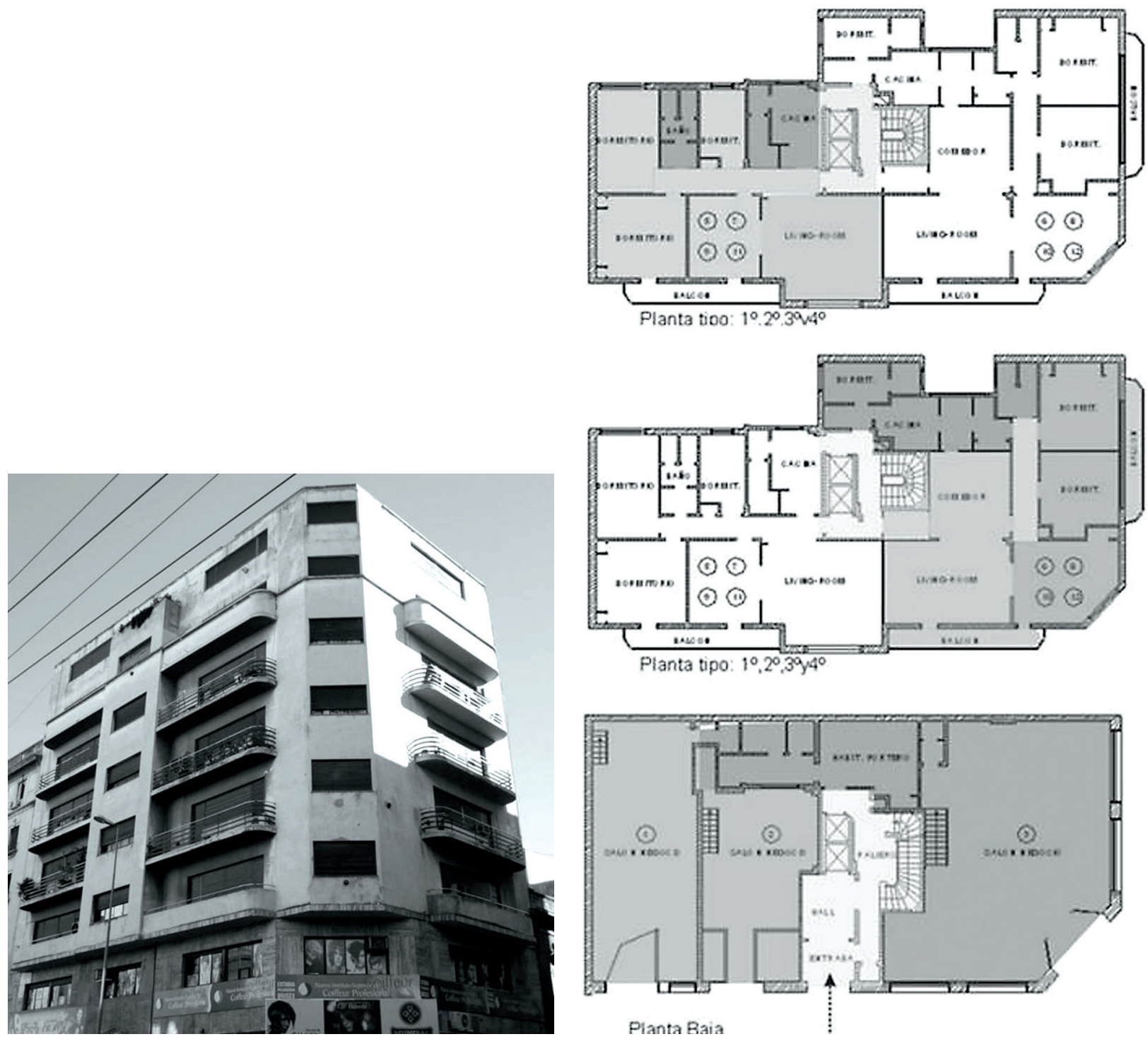

Figura 4. Fachada del edificio de la compañía de seguros La Continental. Figura 5. Plantas del edificio de la compañía de seguros La Continental . 


\section{Edificio Minetti (1940).}

Avenida Hipólito Irigoyen 27. Arquitecto: Joaquín Rezoagli. Esta construcción en altura para uso residencial, de nueve niveles y con una unidad habitacional en cada piso, está ubicada entre medianeras y dispone de locales comerciales y cocheras en la planta baja. Se localiza en un terreno irregular, consecuencia del trazado en diagonal de la división predial de la manzana. La fachada exhibe organización simétrica y racional, los balcones curvos acentúan el eje de simetría de la composición -aún académica- que se expresa en el lenguaje despojado de detalles, característico del movimiento moderno en esta ciudad.
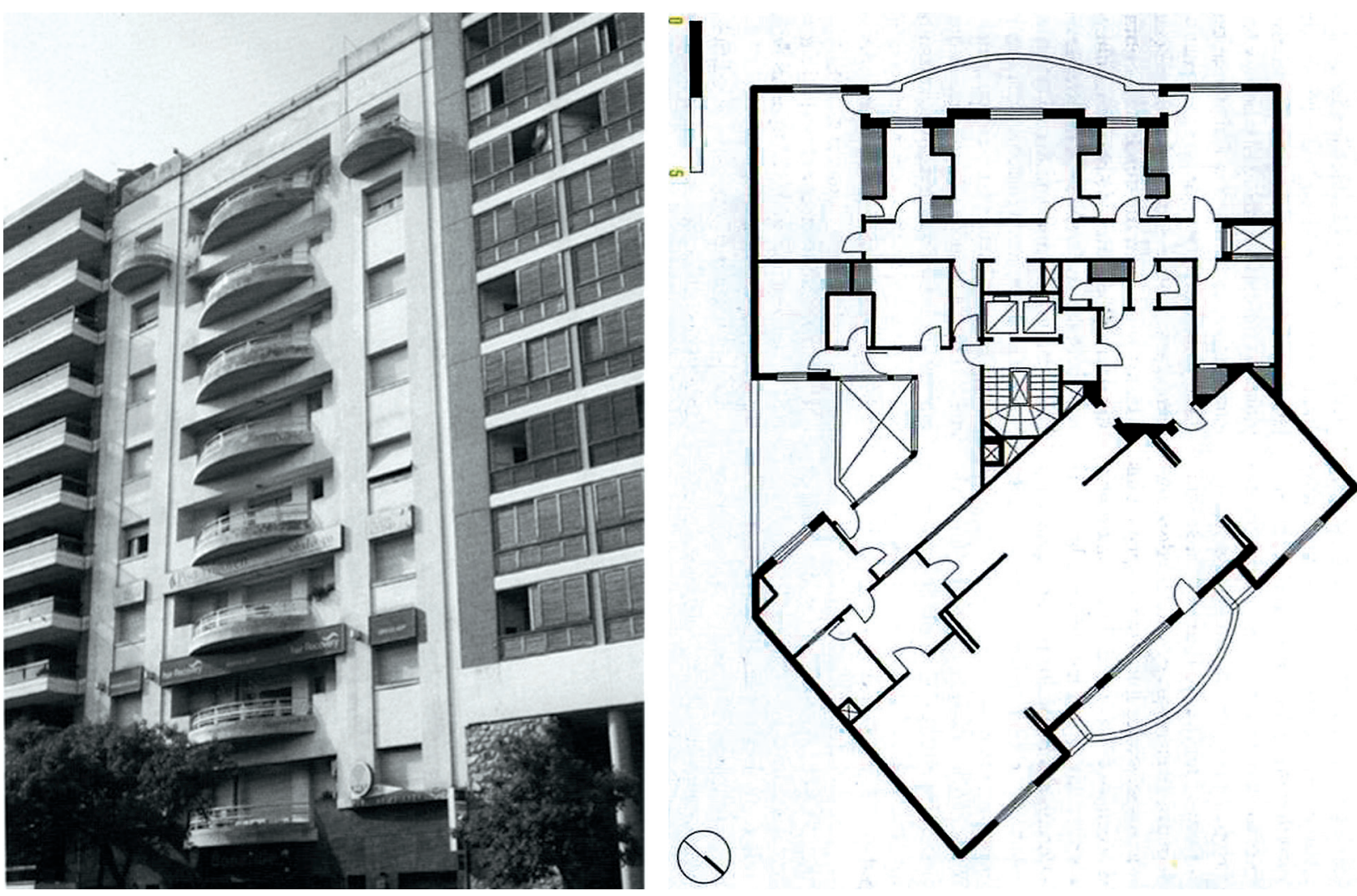

Figura 6. Fachada del edificio Minetti.

Figura 7. Planta tipo del edificio Minetti.

Fuente: autores. 


\section{TIPOS ARQUITECTÓNICOS}

Según Waisman (1995) el tipo arquitectónico puede definirse como un sistema de relaciones topológicas entre elementos espaciales y formales que se corresponde con un sistema de coordinación de funciones y un sistema estructural sin definiciones formales precisas. Se forma por abstracción de diversos edificios o por generalización de una creación individual y en su origen está ligado a condiciones históricas y en ocasiones a propuestas generales, a partir de las cuales se constituye una carga significativa. Puede afirmarse que las primeras construcciones racionalistas de Córdoba, concebidas como edificios de rentas, insertas en distintas situaciones y localizadas en una trama urbana, son planteadas desde un esquema saturado de ocupación de parcela y un cuerpo compacto de no más de diez niveles.

El planteo tipológico es claro: en la planta baja se dispone el palier de ingreso, el núcleo de circulaciones verticales y el área destinada a funciones comerciales y, eventualmente, residenciales. Los pisos superiores, con una o dos unidades habitacionales por nivel, están diseñados según un criterio funcionalista del que derivan plantas compactas. Un estudio minucioso de las circulaciones interiores rige la distribución de los usos y la disposición de los locales en cada unidad. Así, hay una notoria diferenciación por sectores: de servicios (cocina, lavadero y cuartos de personal), público, social y privado (dormitorios). Para Liernur (2001), al provocar la especialización de los usos y las funciones del habitar doméstico, la modernización traza una separación entre el mundo exterior público y el privado.

El principal rasgo reconocible en las unidades es la "compactación de la planta", referida a la reducción de las superficies de los espacios y su integración en zonas con características nuevas como el living room. Además, los servicios (cocina y baño) se incorporan en el interior, gracias a los avances tecnológicos y la tecnificación de las tareas domésticas. Tal compactación no hubiera sido posible sin los cambios culturales que llevaron a aceptar e incluso a desear la vida residencial en ámbitos de dimensiones más pequeñas. Al respecto, Álvarez de Toledo (2011) afirma que, para distintos sectores, la vivienda y sus maneras de habitar adquirieron cada vez más preponderancia, pues su valor simbólico se intensificó y determinó la posición del individuo dentro de la sociedad.

A través de rasgos constructivos y espaciales, de características y cualidades de las unidades, de sus espacios destinados a lo social (comedor, sala, living), las distintas clases sociales -sobre todo la media- buscaron pertenecer a un grupo distinguido. Se crearon así imaginarios acerca del habitar y estas representaciones simbólicas vieron su expresión y concreción en el departamento moderno. 


\section{CONCEPCIONES ESPACIALES}

Con la llegada de la modernidad, el espacio doméstico se redujo, se abrió y se concibió más transparente. De forma paralela, los modos de interacción y los roles jerárquicos de los integrantes del grupo doméstico se transformaron. La vivienda y las maneras de habitar cobraron cada vez más relevancia al contener valores simbólicos que indicaban la "posición" social. Mediante las cualidades de las unidades y sus espacios, en particular los utilizados para la sociabilidad, la clase media aspiraba a acceder a otro grupo. A medida que el periodo avanzó, este imaginario llevó a asociar la idea de un tipo específico de vivienda con un estatus particular, capacidad económica y una identificación con ciertos valores e ideales.

Así, al indagar sobre las ceremonias sociales y los ritos que tienen lugar al interior de las unidades habitacionales a medida que la sociedad va adoptando costumbres más "refinadas" como parte de un proceso de cambio influido por la modernidad, se encuentra un incremento de la importancia y sofisticación de prácticas del cuerpo (aseo, higiene y cuidado), de la mano de los adelantos tecnológicos. El comedor, por su parte, sigue siendo el primer lugar de la vida familiar y alrededor de la mesa tradicional la sociedad toma forma, cuerpo y rostro. El rito de comer y su protocolo determinan la ubicación en el departamento de este espacio, el cual reúne un carácter ambiguo entre público y privado debido a su necesidad de conexión con otras partes más reservadas como la cocina y los lugares destinados a la recepción.

Al seguir a Ballent y Liernur (2014) y entender que en la casa convergen variables sociales, económicas, tecnológicas, ideológicas e incluso políticas, puede verse en ella un poderoso objeto en la construcción de imaginarios sociales, particularmente en la modernidad. Cuando la velocidad de los cambios tecnológicos y culturales potenciados por la amplificación de los circuitos y los medios de comunicación estimula la constante renovación de paradigmas de habitación, la casa se emplea como medio para prefigurar los tiempos por venir.

En este contexto, Álvarez de Toledo (2011), afirma que las búsquedas en el diseño de departamentos se centraron en articular los sectores sociales con los de uso íntimo, además de introducir profundas transformaciones en baños y cocinas, al ser estos dispositivos paradigmáticos en las nuevas formas del habitar moderno. 


\section{LENGUAJES}

Los lenguajes analizados en todos los casos de estudio presentan una clara adhesión a lo moderno a través de recursos como el aventanamiento horizontal, el despojo de ornamentación, los materiales empleados, la calidad de los detalles constructivos, la utilización de la curva y las formas alusivas a lo aerodinámico, a lo naval o al expresionismo alemán. Aun así, se observa que subyacen elementos pertenecientes a la composición académica, entre estos la simetría, las particiones horizontales y verticales, la organización en basamento, cuerpo y coronamiento, todo lo cual es propio de la formación de cada autor, tal como se reseña en el cuadro 1 para Jaime Roca y Antonio Vilar. Los balcones se agrupan para conformar cuerpos verticales con losas voladas, figuras curvas y barandas rectas, o bien la horizontalidad se enfatiza mediante el aventamiento corrido. Estas mezclas entre lo vanguardista y lo tradicional resultan características de las indagaciones de aquella primera modernidad y dan cuenta de las distintas acepciones de lo moderno -concepto muchas veces homogeneizado y reducido- al igual que de su carácter de conjunto diverso y heterogéneo en experiencias, modelos y genealogías.

\begin{tabular}{|c|c|}
\hline $\begin{array}{l}\text { Jaime Roca } \\
\text { Cordoba, } 1899 \text { - Id., 1970. Inició sus estudios universitarios en la } \\
\text { Carrera de Ingenieria, en la Facultad de Ciencias Exactas de la } \\
\text { Universidad Nacional de Cordoba. Continuó sus estudios en la } \\
\text { Universidad de Michigan, donde se graduó como arquitecto. } \\
\text { Colaboró paralelamente en otras Instituciones norteamericanas y } \\
\text { en estudios profesionales. La experiencia adquirida le permitió } \\
\text { desarrollar, en su regreso a Córdoba, una importante labor } \\
\text { protesional. En su primerperiodo realizo obras dentro de la corriente } \\
\text { Neocolonial para desarrollar luego obras de la modernidad } \\
\text { arquitectónica. Su primera adhesión al Estilo Internacional se } \\
\text { evidencia en su casa particular, con reinterpretaciones de los } \\
\text { postulados modernos adecuándolos a la realidad cordobesa y sus } \\
\text { requerimientos particulares. }\end{array}$ & $\begin{array}{l}\text { Obras del Movimiento Moderno } \\
\text { Cordoba: } \\
\text { Casa del arquitecto (1934-35); Edificios de departamentos; } \\
\text { Hotel Crillon (1952);Galeria Argentina (1956). } \\
\text { Tucumán: } \\
\text { Policlinico Ferroviario de Tucumán (1940). }\end{array}$ \\
\hline $\begin{array}{l}\text { Antonio Ubaldo Vilar } \\
\text { La Plata, } 1887 \text { - Bs. As., 1966. Formado en la Facultad de } \\
\text { Ingenieria, la obra de Antonio Vilar, se ha caracterizado por la } \\
\text { impronta ingenieril, su vinculación con empresas de la construcción } \\
\text { alemanas, y la sobriedad atribuida a su arquitectura a partir del } \\
\text { sólido manejo de nuevos elementos lingūisticos y funcionales } \\
\text { presentes en toda su producción racionalista. }\end{array}$ & $\begin{array}{l}\text { Obras del Movimiento Moderno } \\
\text { Argentina: } \\
\text { Estaciones delAutomóvili Club ArgentinoACA-YPF; } \\
\text { Buenos Aires: } \\
\text { Hindú Club (1931); Hospital Churruca (1938); Banco } \\
\text { Holandés Unido (1937); Casas de renta (1935); viviendas } \\
\text { individuales (1931); entre las más importantes. } \\
\text { Córdoba: } \\
\text { Edificios de departamentos y Sedes delACA-YPF }\end{array}$ \\
\hline
\end{tabular}




\section{TECNOLOGÍAS}

Las nuevas tecnologías destinadas al confort, tales como ascensores, calefacción, incineradores, servicios centrales de agua caliente, mecanismos para la disposición de residuos, secadoras de ropa, la misma cocina eléctrica o de gas y en ocasiones las heladeras con equipo centralizado, fueron rápidamente incorporadas en los edificios modernos y asimiladas por los usuarios en su cotidianidad. El imaginario de la época, constituido por una serie de mitos sobre el progreso, la eficiencia, el orden, la limpieza, la sobriedad y la tecnología, se convirtió en un paradigma de vida en que la idea de lo funcional, confortable, eficiente y salubre era primordial.

Para Álvarez de Toledo (2011), los preceptos del MoMo instalaron el ideal de confort, bienestar y prestigio a través del cine, la radio, las revistas y, más tardíamente, la televisión. Por otra parte, Ballent (1999) afirma que la modernización del hogar liberó a las mujeres de numerosas tareas domésticas y redujo los tiempos de ejecución de muchas otras. El ritmo de la vida moderna y, fundamentalmente, la escasez de tiempo y de voluntad para ocuparse de los quehaceres de la casa llevó a que la vivienda de la mujer fuera cómoda y eficiente, pero sobre todo, fácil de operar, mantener y limpiar.

\section{RELACIÓN CON LA CIUDAD}

En los casos analizados es evidente que la generación y conformación de la tipología, así como la distribución y las dimensiones de las unidades habitacionales, responden de forma directa a los lotes y sus características morfológicas: aquellos situados en esquina permiten mayores superficies de iluminación y ventilación de los ambientes principales, mientras que los ubicados entre medianeras solo posibilitan tales propiedades en algunos ambientes, con la consecuente necesidad de crear patios de aire y luz para los espacios de segunda categoría.

Como sostiene Rodriguez de Ortega (2012), la arquitectura moderna supo adaptarse al tejido urbano, mediante un respetuoso diálogo, partir del sentido de la estética urbana, que tuvieron los arquitectos encargados, conocedores del oficio y de aquellas nuevas formas de composición. Se dotó así, al espacio doméstico de una mayor transparencia y permeabilidad mediante el recurso de balcones y terrazas. 
Un nuevo concepto de lugar se instaló frente a un contexto transformado y totalmente innovador. No había fronteras, no existían límites ni bordes que definieran un vacío, como pasaba cuando antiguamente se estructuraban los espacios colectivos y privados. Por el contario, en este nuevo escenario el vacío era lo esencial. El espacio público se volvió casi infinito, sin elementos físicos que lo contuvieran y a su arquitectura se le permitió dialogar a través de intercambios de miradas. Por ende, la percepción de escala también se renovó, pues las grandes proporciones de áreas abiertas -ausentes en la ciudad histórica- modificaron la referencia para percibir la verdadera dimensión de las masas edilicias, en tanto lo monumental, en algunos casos, pasó más desapercibidas (Solano Rojo, 2009).

\section{CONCLUSIONES}

Tras considerar la importancia del estudio de las tipologías arquitectónicas como resultado y parte de procesos históricos específicos, hemos indagado en posibles elementos de la identidad latinoamericana y su relación con fenómenos de transculturación. Especialmente, nos hemos preguntado por las características de la modernidad en relación con las trasformaciones que se dan en Córdoba y con las tipologías de vivienda en altura surgidas en los años treinta y cuarenta.

Los procesos culturales y tecnológicos generaron nuevas tipologías debido a los cambios en los modos de habitar, producidos por los paradigmas y costumbres sociales y culturales que irrumpieron, como también debido a los adelantos tecnológicos, pues estos implicaron una modernización de las tareas del hogar.

Ballent (1999) sostiene que las casas de departamentos, desarrolladas en altura y portadoras de una imagen caracterizada por la austeridad modernista de sus fachadas blancas y lisas, constituyeron un símbolo de cuanto se consideraba el habitar doméstico metropolitano, inserto en la gran ciudad, participante de su dinámica y que permitía a sus habitantes descubrir un nuevo y privilegiado punto de vista para el disfrute del espectáculo metropolitano: la altura.

Como observa Rodríguez de Ortega (2012), la arquitectura del MoMo en Córdoba se insertó equilibradamente en el contexto, al tiempo que puso de manifiesto las nuevas geometrías de volúmenes puros y superficies limpias.

En este marco, el estudio del tipo de la vivienda en altura evidencia los procesos de transculturación propios del MoMo en Córdoba y ofrece referencias para la enseñanza de la historia y del diseño arquitectónico, ya que permite reflexionar acerca de la construcción del espacio urbano, la innovación tipológica y tecnológica, y el manejo original y funcional del espacio interior. 


\section{REFERENCIAS BIBLIOGRÁFICAS}

Alcalá, L. (Comp.). (1995). Pensar la vivienda. Madrid: Ágora-Talasa.

Álvarez de Toledo, F. (2011). La tipología departamento y la construcción del habitar moderno: Buenos Aires (1930-1960). Cuadernos de Vivienda y Urbanismo, 4(8), (pp.187-192).

Ballent, A. (1999). La casa para todos: grandeza y miserias de la vivienda masiva. En M. Madero \& F. Devoto (Comps.). Historia de la vida privada en Argentina. Tomo III (pp. 19-48). Buenos Aires: Taurus.

Ballent, A. \& Liernur, J. (2014). La casa y la multitud: vivienda, política y cultura en la Argentina moderna. Buenos Aires: Fondo de Cultura Económica, Argentina.

Casal, S. \& Worden, S. (2004). El patrimonio del movimiento moderno en Buenos Aires, 1929-2004. Buenos Aires: Universidad de Belgrano. Disponible en http://www.ub.edu.ar/investigaciones/dt_nuevos/121_casal.pdf

Colautti, V. (2002). Orden y complejidad como instrumentos estratégicos del proceso de diseño en el paisaje urbano del siglo XXI. Tesis de Maestría, Universidad Nacional de Córdoba, Argentina.

Diaz Terreno, F. (s.f.). El lugar de todos. Consideraciones sobre el área central de la ciudad de Córdoba. Recuperado de http://www.cafedelasciudades.com.ar/planes_104.htm

Doberti, R. (2008). Espacialidades. Buenos Aires: Infinito.

Iglesia, R. (2006). El espacio doméstico. Buenos Aires: I+P. 
Liernur, F. (2001). Arquitectura en la Argentina del siglo XX: la construcción de la modernidad. Buenos Aires: Fondo Nacional de las Artes.

Martínez Nespral, F. (2012). Setenta balcones y ninguna flor. En M. Arias Incolla (Ed.). Edificios de departamentos, conjuntos y viviendas colectivas. Tomo 7 de Patrimonio Argentino (pp. 8-15). Buenos Aires: Arte Gráfico Editorial Argentino.

Montaner, J. (2011). Arquitectura y crítica en Latinoamérica. Buenos Aires: Nobuko.

Rodríguez de Ortega, A. (2012). Edificio Minetti: lenguaje despojado y tensión horizontal. Patrimonio Argentino: Edificios de Departamentos, conjuntos y casas colectivas, (07). Buenos Aires: Clarín 2012. (pp.96- 99)

Rojas Mix, M. (2004). Los cien nombres de América. Eso que descubrió Colón. Córdoba, Argentina: Universidad Nacional de Córdoba.

Romero, L. (1997). Latinoamérica: las ciudades y las ideas. Buenos Aires: Siglo Veintiuno.

Scarone, M. (2008). Aproximación al Movimiento Moderno: una experiencia en la Universidad de Buenos Aires. En S. M. Casal, V. Garello, M. Gigli \& S. Worden (Eds.). El Patrimonio del Movimiento Moderno: pensamientos, reflexiones, aprendizajes (pp. 18-26). Buenos Aires: Universidad de Buenos Aires.

Solano Rojo, M. (2009). Modelos prestados. Evolución de la vivienda colectiva después del Movimiento Moderno. Trabajo de investigación de Doctorado, Universidad de Málaga, Málaga, España.

Taberna, J. (2008). La Casa. Cuaderno Latinoamericano de arquitectura 30-60, (17). Córdoba. I+p editorial. (pp. 28-33)

Waisman, M. (1995). La arquitectura descentrada. Historia y teoría Latinoamericana. Bogotá: Escala.

Yujnovsky, O. (1984). Claves políticas del problema habitacional argentino 1955-1981. Buenos Aires: Consejo Latinoamericano de Ciencias Sociales. 